\title{
PENDIDIKAN KARAKTER DALAM PEMENTASAN DRAMA "PELAYARAN MENUJU IBU” KARYA RAMLI PRAPANCA SEBAGAI BAHAN AJAR PENGKAJIAN DRAMA MAHASISWA PBSI
}

\author{
Luthfa Nugraheni, Mohammad Noor Ahsin \\ Universitas Muria Kudus \\ Email: luthfa.nugraheni@umk.ac.id
}

\begin{abstract}
The objectives of this study were (1) to describe the form of character education in the drama "Pelayaran Menuju Ibu" written by Ramli Prapanca as teaching material for the Study of Drama for students of PBSI semester III Muria Kudus University, (2) to describe the relationship between character education as a means of social control in society through performances the drama "Pelayaran Menuju Ibu" written by Ramli Prapanca to PBSI semester III students of Muria Kudus University. The type in this research is descriptive qualitative. To obtain data in this study, the authors used observation, interview, and documentation techniques. So observations are made to obtain data from the beginning to the end in the research, interview techniques are used to track information-notes so that what is expected can be found. Furthermore, the last technique is documentation which is a tool for collecting data in the form of records of good events in the form of writing, pictures, data visualization and so on. The data analysis technique used in this research is descriptive analysis from the beginning to the end of the study using a framework of tradition discovery and Foucault's discourse analysis. Of the eighteen existing character educations, only seventeen exist in the form of implementation in the performance towards the work of Ramli Prapanca among other religious, honest, tolerance, discipline, hard work, creative, independent, democratic, curiosity, national spirit, love the motherland, appreciate achievement, friendly and communicative, love peace, reading, care about social and responsibility.
\end{abstract}

Keywords: character education; drama; social control

\begin{abstract}
ABSTRAK
Tujuan dalam penelitian ini adalah (1) mendeskripsikan bentuk pendidikan karakter dalam pementasan drama "Pelayaran Menuju Ibu" karya Ramli Prapanca sebagai bahan ajar Pengkajian Drama mahasiswa PBSI semester III Universitas Muria Kudus, (2) mendeskripsikan keterkaitan pendidikan karakter sebagai alat kontrol sosial dalam masyarakat melalui pementasan drama "Pelayaran Menuju Ibu" karya Ramli Prapanca pada mahasiswa PBSI semester III Universitas Muria Kudus. Jenis dalam penelitian ini termasuk deskriptif kualitatif. Untuk memperoleh data pada penelitian ini, penulis menggunakan teknik observasi, wawancara, dan dokumentasi. Jadi teknik observasi dilakukan untuk memperoleh data awal sampai akhir dalam penelitian, teknik wawancara digunakan untuk menelusuri informasi sedalamdalamnya sehingga apa yang diharapkan bisa ditemukan.. Selanjutnya, teknik yang terakhir adalah dokumentasi yang merupakan alat untuk mengumpulkan data-data berupa catatan-catatan peristiwa baik yang berupa tulisan, gambar, data visualisasi dan sebagainya. Teknik analisis data yang digunakan dalam penelitian ini adalah analisis deskriptif dari awal sampai akhir penelitian dengan menggunakan kerangka invention of tradition dan analisis wacana Foucault. dari ke delapan belas pendidikan karakter yang ada, hanya tujuh belas yang ada dalam bentuk implementasi dalam pementasan pelayaran menuju ibu karya Ramli Prapanca antara lain religius, jujur, toleransi, disiplin, kerja keras, kreatif, mandiri, demokratis, rasa ingin tahu, semangat kebangsaan, cinta tanah air, menghargai prestasi, bersahabat dan komunikatif, cinta damai, gemar membaca, peduli sosial dan tanggung jawab.
\end{abstract}

Kata Kunci: pendidikan karakter; drama; alat kontrol sosial

Submitted Nov 25, 2020 | Revised Des 23, 2020 | Accepted Des 29, 2020

\section{Pendahuluan}

Di era globalisasi saat ini, kondisi Indonesia mengalami kemunduran karakter yang sangat kompleks. Munculnya perilaku-perilaku yang menyimpang baik dari kalangan anak Sekolah Dasar (SD), Sekolah Menengah Pertama (SMP), Sekolah Menengah Atas (SMA), bahkan sampai kalangan Mahamahasiswa membuat para orang tua dan masyarakat semakin resah. Kondisi seperti ini dikuatkan dengan adanya berita di media massa yang mengangkat masalah kriminalitas yang kian hari kian marak. 
Penyalah gunaan obat-obatan terlarang, konsumsi miras, pelecehan seksual, tawuran, terorisme, mahamahasiswa mencontek saat ujian, bocornya kunci jawaban ketika ujian, bahkan sampai mahamahasiswa yang merokok, tindakan korupsi dan sampai ketidak santunan para pejabat teras maupun figur artis mengironiskan tentang kemunduran karakter yang mengakar.

Hal ini menunjukkan kemerosotan yang sangat berarti karena Bangsa dan Negara yang maju terlihat dari pembentukan karakter tiap-tiap Sumber Daya Manusianya (SDM). Dekadensi nilai moral yang merosot menunjukkan betapa kurangnya penanaman pendidikan karakter di sekolah. Dengan adanya fakta-fakta yang terjadi, Bangsa ini harus segera menemukan solusi yang tepat dan terbaik untuk menguraikan serta mengatasi masalah yang sangat kompleks ini. Pendidikan karakter berbasis sastra merupakan salah satu solusi yang dianggap pas untuk mengatasi masalah-masalah tesebut.

Menurut Khan (2010:1) kata pendidikan adalah sebuah proses yang membantu menumbuhkan, mengembangkan, mendewasakan, menata dan mengarahkan. Hal ini dapat dipertegas bahwa pendidikan merupakan pilar penting yang bertujuan untuk menumbuhkan dan mengembangkan ilmu serta kemampuan seseorang. Khan (2010:1) juga menjelaskan karakter merupakan sikap pribadi yang stabil hasil proses konsolidasi secara progresif dan dinamis. Oleh sebab itu karakter dikatakan sebagai kualitas atau kekuatan mental atau moral yang merupakan kepribadian khusus yang menjadi pendorong dan penggerak serta membedakan individu satu dengan yang lain.

Meskipun pendidikan karakter bukan sepenuhnya menjadi tanggung jawab instansi pendidikan, namun di Perguruan Tinggi memiliki peran sangat penting dalam membentuk karakter mahamahasiswa. Dengan pendidikan berbasis sastra mahamahasiswa akan diajarkan bagaimana memanusiakan manusia. Di dalam sastra, mahamahasiswa juga akan menjumpai dongeng, hikayat, mantra, puisi, novel, maupun drama. Tetapi pada penelitian ini hanya terfokus pada pembentukan karakter dalam sebuah pementasan drama sebagai alat kontrol dalam masyarakat.Salah satu bentuk karya sastra yang ingin diteliti adalah drama. Menurut Dewojati (2012:16) drama merupakan bentuk karya sastra yang digemari oleh masyarakat luas. Hampir setiap masyarakat di setiap pelosok dunia telah akrab dengan drama. Drama memiliki keistimewaan tersendiri dibandingkan genre sastra lainnya. Hal itu disebabkan karena drama diciptakan untuk dipentaskan dan diamati secara bersama-sama.

Naskah drama yang dipilih untuk dipentaskan adalah karya dari Ramli Prapanca yang berjudul "Pelayaran Menuju Ibu". Mengapa judul ini terpilih untuk dipentaskan dari pada judul drama yang lain yakni, drama ini mengangkat tema tentang rasa toleransi yang tinggi. Hal ini lah yang membedakannya dengan naskah drama lainnya. Selain itu drama ini juga menceritakan bagaimana perjuangan kedua pemuda yang menjunjung tinggi persahabatann guna bersama-sama mencari jati dirinya. Merujuk dari pengertian tersebut drama merupakan suatu genre sastra yang ditulis dalam bentuk dialog-dialog dengan tujuan untuk dipentaskan sebagai suatu seni pertunjukkan. Di dalam pertunjukan tersebut mahamahasiswa mampu mengenal bagaimana watak, karakter, dan kebribadian dari masing-masing tokoh. Hal ini juga dapat mempertegas bawasannya pementasan drama mampu menjadi suatu alat untuk membantu mengarahkan mahamahasiswa pada suatu tatanan yang bermakna sehingga, mahamahasiswa mampu terhindar dari terpelesetnya Bangsa yang mengalami jurang kebobrokan moral.

Universitas Muria Kudus merupakan salah satu kampus swasta yang terbesar di jalan Pantura Jawa Tengah. Tentu dalam hal ini untuk memupuk dan membentuk karakter mahamahasiswa yang kuat, maka diperlukan pendidikan karakter. Upaya pembentukan karakter mahamahasiswa Pendidikan Bahasa dan Sastra Indonesia, maka dalam hal ini akan diberikan stimulus melalui vidio pementasan drama yang berjudul "Pelayaran Menuju Ibu" sebagai alat kontrol mahamahasiswa di lingkungan masyarakat. Tidak dapat dipungkiri bahwa pengaruh terbesar tentang kemunduran karakter salah satunya adalah lingkungan masyarakat. Apabila mahamahasiswa tidak dibekali pendidikan karakter yang kuat, maka mental mereka suatu saat akan mudah terbawa arus. Berdasarkan latar belakang di atas, maka penulis tertarik untuk meneliti Nilai Pendidikan Karakter dalam Pementasan Drama "Pelayaran 
Menuju Ibu" Karya Ramli Prapanca pada Mahamahamahasiswa PBSI Semester III Universitas Muria Kudus.

\section{Metode Penelitian}

Jenis penelitian ini adalah deskriptif kualitatif. Penelitian kualitaitf adalah metode yang memberikan perhatian terhadap data alamiah, data dalam hubunganya dengan konteks keberadaannya (Ratna, 2007:47). Data dari penelitian ini adalah mahasiswa Pendidikan Bahasa dan Sastra Indonesia, Universitas Muria Kudus semester III yang berjumlah 30 mahasiswa. Strategi yang digunakan dalam penelitian ini adalah studi kasus terpancang. Teknik pengumpulan data yang dipakai dalam penelitian ini adalah teknik observasi, wawancara, dan dokumentasi. Teknik analisis data yang digunakan dalam penelitian ini adalah analisis deskriptif dari awal sampai akhir penelitian dengan menggunakan kerangka invention of tradition dan analisis wacana Foucault.

\section{Hasil dan Pembahasan}

Pendidikan karakter merupakan cara berpikir dan berperilaku yang menjadi ciri khas setiap orang untuk hidup dan bekerja sama, baik dalam lingkup keluarga, masyarakat, Bangsa maupun Negara. Pendidikan karakter dalam dewasa ini sangat relevan untuk mengatasi krisis moral yang sedang melanda Bangsa Indonesia. Tujuan dari pendidikan karakter ini adalah membentuk bangsa yang tangguh, kompetitif, berakhlak mulia, bermoral, bertoleran, bergotong royong, berjiwa patriotik, berkembang dinamis, berorientasi ilmu pengetahuan dan teknologi yang semuanya dijiwai oleh iman dan ketakwaan kepada Tuhan Yang Maha Esa berdasarkan Pancasila.

Pratiwi (2016) membangun karakter dan rasa multikultural dapat pula dibentuk melalui film animasi yang mengkaitkan nilai-nilai multikultural sehingga menumbuhkan rasa menghargai dari setiap perbedaan yang ada. Merujuk dari penelitian Partiwi di atas, dalam artikel ini menambahkan bahwa selain rasa multikulturalisme juga diperlukan pendidikan karakter pada generasi penerus untuk mempersiapkan pribadi yang kuat. Macam-macam pendidikan karakter dalam penelitian ini ada delapan belas, antara lain: (1) religius, (2) jujur, (3) toleransi, (4) disiplin, (5) kerja keras, (6) kreatif, (7) mandiri, (8) demokratis, (9) rasa ingin tahu, (10) semangat kebangsaan, (11) cinta tanah air, (12) menghargai prestasi, (13) bersahabat/komunikatif, (14) cinta damai, (15) gemar membaca, (16) peduli lingkungan, (17) peduli sosial, (18) tanggung jawab. Berikut rinciannya:

Tabel 1. Bentuk implementasi pendidikan karakter dalam pementasan drama Pelayaran Menuju Ibu karya Ramli Prapanca

\begin{tabular}{lll}
\hline No & \multicolumn{1}{c}{$\begin{array}{c}\text { Nilai Pendidikan } \\
\text { Karakter }\end{array}$} & \multicolumn{1}{c}{ Bentuk Implementasi } \\
\hline 1 & Religius & 1 Taat Beribadah \\
2 & Jujur & 2 Izin berhalangan hadir \\
3 & Toleransi & 3 Menerima kemenangan lawan \\
4 & Disiplin & 4 Patuh pada perintah \\
5 & Kerja Keras & 5 Pantang Menyerah \\
6 & Kreatif & 6 Membuat musik pengiring drama \\
7 & Mandiri & 7 Dapat menyelesaikan tugas \\
8 & Demokratis & 8 Berdiskusi bersama teman \\
9 & Rasa Ingin Tahu & 9 Memberi hal positif \\
10 & Semangat Kebangsaan & 10Melaksanakanlomba"Kepahlawanan" \\
11 & Cinta Tanah Air & 11 Membaca teks Proklamasi \\
12 & Menghargai Prestasi & 12 Menerima kemenangan lawan \\
13 & Bersahabat dan Komunikatif & 13 Berbaur dengan teman baru \\
14 & Cinta Damai & 14 Cinta kasih kepada sesama \\
15 & Gemar Membaca & 15 Melaksanakan program literasi \\
\hline
\end{tabular}




\begin{tabular}{lll}
16 & Peduli Lingkungan & 16 \\
17 & Peduli Sosial & 17 Menolong Ibu \\
18 & Tanggung Jawab & 18 Merawat Ibu yang sakit \\
\hline
\end{tabular}

Dari ke delapan belas pendidikan karakter di atas ada satu nilai pendidikan karakter yang masuk ke dalam implementasi pementasan pelajaran menuju ibu, yakni peduli lingkungan. Hal ini disebabkan karena dalam cerita tersebut hanya menampilkan dan menceritakan bagaimana seorang anak hidup tanpa seorang ibu dan kemudian bersekolah lalu mendapatkan tugas dari gurunya untuk membuat kegiatan untuk memperingati hari pahlawan. Ilminisa menambahkan bahwa selain karakter anak terbentuk dari drama, pembentukan karakter juga dapat ditanamkan melalui cerita rakyat lokal di setiap daerah. Hal ini bertujuan dijadikan rujukan bacaan setiap anak, sehingga anak dapat menangkap pesan moral dan karakter yang dimiliki setiap pemain.

Macam-macam implementasi pendidikan karakter dalam pementasan drama di atas dapat disimpulkan cikal bakal untuk menghantarkan generasi muda khususnya bagi mahasiswa agar dapat membawakan diri dalam bermasyarakat maupun dalam dunia pekerjaan nantinya. Pendidikan merupakan usaha yang sadar, terencana, sistematis, dan berlangsung secara terus menerus dalam suatu proses pembelajaran guna mengembangkan seluruh potensi manusia baik secara jasmani maupun rohani dalam tingkatan kognitif, afektif, dan psikomotorik. Pendidikan secara tidak langsung dapat diajarkan di sekolah, rumah, maupun masyarakat, akan tetapi pendidikan karakter bermula dari dukungan dan ajaran orang tua terhadap anak.

Dewasa ini kerap terjadi tindakan-tindakan kriminalitas yang marak di Indonesia. Selain itu, banyak budaya-budaya luar yang secara mudah menyerang mental generasi muda Indonesia. Hal ini merupakan tamparan keras bagi pemerintah, masyarakat, guru terutama orang tua yang harus terlebih dahulu menekankan pendidikan karakter pada anak sejak dini. Agar generasi muda penerus bangsa ini tidak mudah tergerus oleh lajunya perkembangan globalisasi sekarang ini.

Pendidikan karakter merupakan pendidikan yang wajib diberikan kepada anak sejak dini. Melalui pendidikan karakter ini diharapkan anak-anak dapat mempersiapkan diri pada arus globalisasi dan pengaruh budaya barat maupun tindakan-tindakan kriminalitas. Dalam pendidikan karakter tentu saja mengajarkan seseorang agar bisa bersikap jujur, religius, tanggung jawab, peduli pada lingkungan, cinta damai pada sesama dan lain sebagainya. Melalui pendidikan karakter dalam pementasan drama Pelayaran Menuju Ibu tersebut dapat menjadikan mahamahasiswa PBSI UMK semester III dan generasi muda Indonesia dapat berbaur dan membawakan diri di lingkungan masyarakat dengan menjunjung nilai etika dan norma yang berlaku.

Di bawah ini akan dijelaskan keterkaitan pendidikan karakter sebagai alat kontrol sosial dalam masyarakat melalui pementasan drama Pelayaran Menuju Ibu karya Ramli Prapanca pada mahamahasiswa PBSI UMK semester III Pendidikan karakter sebagai alat sosialisasi dalam bermasyarakat. Salah satunya adalah (1) Pendidikan karakter sebagai alat mengontrol emosi seseorang dalam bermasyarakat. (2) Pendidikan karakter sebagai alat pelestarian budaya dalam masyarakat. (3) Pendidikan karakter sebagai alat untuk latihan dalam pengembangan tenaga kerja dalam bermasyarakat. (4) Pendidikan karakter sebagai alat untu perubahan sosial dalam masyarakat dengan memperhatikan norma yang berlaku.

Dari uaraian tentang keterkaitan pendidikan karakter sebagai alat kontrol sosial dalam masyarakat melalui pementasan drama Pelayaran Menuju Ibu karya Ramli Prapanca pada mahamahasiswa PBSI UMK semester III memiliki nilai positif yang didapat, yakni dapat mendidik mahamahasiswa yang lebih berkualitas sehingga tatanan dalam bermasyarakat dapat terjalin dengan baik dan sebagai alat pemersatu dari segala idiologi yang masing-masing dimilikinya. Melalui pendidikan karakter dalam pentas drama ini mahasiswa juga mampu mengontrol emosi dan tingkah lakunya agar tidak terjadi selisih paham baik diantara teman sebaya maupun orang yang lebih tua. Selanjutnya dengan adanya penggalan adegan pelaksanaan pengibaran bendera sang merah putih dan pembacaan teks proklamasi guna memperingati 
hari Pahlawan secara tidak langsung mengetuk hati mahasiswa agar dapat mengenang perjuangan para pahlawan yang telah bersusah payah dalam merebut kemerdekaan dari tangan penjajah.

Melalui kegiatan pengibaran bendera tersebut mahasiswa juga dapat mempersiapkan diri untuk melawan penjajahan mental yang dihadirkan melalui tontonan di televisi maupun pengaruh budaya luar yang kian hari kian marak menggerogoti mental anak bangsa ini. Melalui pendidikan karakter dalam pementasan drama tersebut, mahasiswa dapat lebih giat dalam menerapkan kedisiplinan dalam penggunaan hp atau bermain game online, tidak terlambat masuk sekolah, dan meyelesaikan tugas tepat waktu dari waktu yang sudah diseakati antara guru dengan mahasiswa.

Melalui pendidikan karakter yang sudah didapatkan melalui pementasan drama tersebut, mahasiswa dapat mengaplikasikannya dalam lingkungan bermasyarakat, di mana mereka kaum muda harus lebih sopan, santun dan menghargai etika atau aturan yang berlaku di masyarakat. Selanjutnya mahasiswa diharapkan mampu untuk lebih bisa menghargai dengan orang yang lebih tua dari umurnya dan bertuturkata yang sopan agar tidak menimbulkan konflik atau salam paham dalam bermasyarakat.

\section{Kesimpulan}

Keterkatitan antara pendidikan karakter sebagai alat kontrol masyarakat adalah Pendidikan karakter sebagai alat sosialisasi dalam bermasyarakat (1) Pendidikan karakter sebagai alat mengontrol emosi seseorang dalam bermasyarakat. (2) Pendidikan karakter sebagai alat pelestarian budaya dalam masyarakat. (3) Pendidikan karakter sebagai alat untuk latihan dalam pengembangan tenaga kerja dalam bermasyarakat. (4) Pendidikan karakter sebagai alat untuk perubahan sosial dalam masyarakat dengan memperhatikan norma yang berlaku. Melalui ke tujuh belas bentuk implementasi pendidikan karakter di atas dapat mendidik dan menjadikan mahasiswa yang lebih berkualitas sehingga tatanan dalam bermasyarakat dapat terjalin dengan baik dengan menjunjung nilai etika dan moral serta sebagai alat pemersatu dari segala aliran dan pandangan hidup yang dianut oleh mahasiswa. Kendala-kendala yang ada (pergantian pemain dan penyediaan waktu pembelajaran pementasan drama) dari proses latihan sampai pementasan tidak menjadikan mahasiswa mahasiswa PBSI UMK semester III surut semangatnya dalam melaksanakan pementasan drama pelayaran menuju Ibu karya Ramli Prapanca.

\section{Daftar Pustaka}

Al-Ma'ruf, Ali Imron. (2010). Dimensi Sosial Keagamaan dalam Fiksi IndonesiaModern. Solo: Smart Media

Dewojati, Cahyaningrum. (2012). Drama: Sejarah, Teori, dan Penerapannya. Yogyakarta: Java Krasa Media

Hidayattullah, Mohammad Furqon. (2009). Guru Sejati: Membangun Insan Berkarakter Kuat dan Cerdas. Surakarta: Yuma Pustaka

Ilminisa, Ranggi Ramadhani. (2016). Bentuk Karakter Anak melalui Dokumentasi Folklore Lisan Kebudayaan Lokal. Jurnal Pendidikan Volume 1 Nomor 6

Nurgiyantoro, Burhan. (2007). Kajian Pengkajian Fiksi. Yogyakarta: Gajah Mada UniversityPress

Nyoman, Kutha Ratna. (2009). Teori, Metode, dan Teknik Penelitian Sastra. Yogyakarta: Pustaka Pelajar

Kementrian Pendidikan Nasional. (2011). Pendidikan Karakter Berbasis Sastra. Jakarta: Direktorat Jendral Pendidikan Dasar

Khan, Yahya. (2010). Pendidikan Karakter BerbasisPotensi Diri. Yogyakarta: Pelangi Publishing.

Pratiwi, Yuni. (2016). Film Animasi Cerita dengan Konteks Multibudaya untuk Mendukung Kekritisan Penalaran Anak Usia SD. Jurnal Litera, Volume 15 Nomor 2.

Sudrajad, Akhmad. (2010). Tentang Pendidikan Karakter Seminar Nasional: Character Bilding for Vocational Education".

Sugiono. (2009). Metode Penelitian Pendidikan Kuantitatif, Kualitatif dan R\&D. Bandung: Alfabeta 
Ruslan, Rosady. (2008). Metode Penelitian Public Relations dan Komunikasi. Jakarta: PT. Raja Grafindo Persada

Rustan, Ibrahim. (2013). Pendidikan Multikultural: Pengertian Prinsip dan Relevansinya dengan Tujuan Pendidikan Islam. Jurnal Unnu Addin Volume 7 No 1. 